\title{
A Study on the Direct-coupled Driving in the Automatic Door System by Very-low Speed Control of DC Motor
}

\author{
Hyun-Chang Lee ${ }^{1}$ and Kyu-Tae Lee $*^{2}$ \\ ${ }^{1}$ Div. of Information \& Communications Kongju National University, Korea \\ ${ }^{2}$ Div. of Information \& Communications Kongju National University, Korea \\ ${ }^{1}$ hclee@kongju.ac.kr, ${ }^{2}$ ktlee@ kongju.ac.kr
}

\begin{abstract}
In this paper, VVPWM (Voltage Varying Pulse Width Modulation) is proposed that direct driven automatic door is controlled smoothly at low speed. In order to prevent vibrations of the doors at low speed, it is more advantageous to have more solenoids on the rotor. An automatic door motor with a $20 \mathrm{~mm} \varnothing$ belt pulley is required to operate from 477.48 RPM to 19.08 RPM. It is possible to control precisely not only high speed operation region but also low speed operation region of the automatic door with VVPWM; high frequency PWM is unnecessary. In order to verify the effectiveness of the $V V P W M$, experimental system is designed as dual PWM generator built into the $20 \mathrm{MHz}$ microcontroller. Experimental results show that the conventional PWM controls an average of 4 RPM over the entire operating range of the motor. On the other hand, the VVPWM controls an average of 0.3 RPM at low speed while applying a high PWM frequency of $78.125 \mathrm{KHz}$. It is notice that VVPWM can control the motor with 13.33 times higher precision than conventional PWM.
\end{abstract}

Keywords: Door; Auto-door; DC-Motor; PWM; VVPWM

\section{Introduction}

The automatic door is widely used at entrance of the building, shopping center, and home use for not only convenience but also energy saving. Also, as security system is combined with automatic door, demand of the automatic door has been increased. The electric motor in the automatic door normally drives at nominal speed. However, it drives at low speed for impact relief as the door is opened and closed. When the analog control is used for speed control of electric motor, the power efficiency is reduced and heat sink should be installed due to heat generation. For this reason, PWM switched control is generally used to control the electric motor. However, PWM control makes the electric motor not rotate or vibrate at low speed. To overcome this problem, a gear reducers conventionally installed on the automatic door in order to drive at low speed. The gear reducer is one of the simplest methods for low speed driving and self-locked when rotated from the load side. However, the friction effect and backlash of gear make energy loss and noise and the weight of driving system is increased. More seriously, self-locked of worm gear causes high mechanical impedance that people cannot escape quickly from a disaster and it turned out to be serious damage and casualties.

Lee proposed that solution of motor driving at low speed technically without gear reducers [1], and analyzed limitations of low speed control, which is related to the PWM switched control [2]. Recently, however, there are a number of researches that efficiency reduction and torque ripple is focused on high speed operation [3]-[8].

In this paper, the requirements of low speed motor control were analyzed in automatic door system. The automatic door was proposed by direct driven to the electric motor, and it can contribute to remove hazards. The proposed automatic door controller has dual PWM generator, which is called VVPWM (Voltage Varying Pulse Width Modulation), 
that contributes the high resolution of speed control especially at low speed. The proposed method is verified with simulations and experimental results.

\section{Analysis}

\subsection{Characteristics and Driving Method of Brush DC Motor}

\subsubsection{Structure and Principle of Brush DC Motor}

Figure 1 shows the principle of rotation of a brush DC motor, and the middle arrow indicates phase a-b. Although, the rotor rotates continuously as shown in the Figure 1(a)(d), a current passes through the coil wound around a core by commutators and brushes. As a result, the current direction of the coil wound is always kept the same [9].

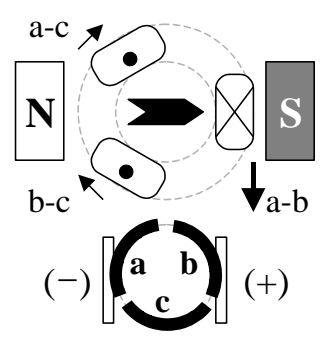

(a) 0-Degree

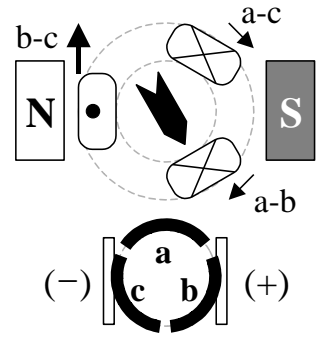

(b) 60-Degrees

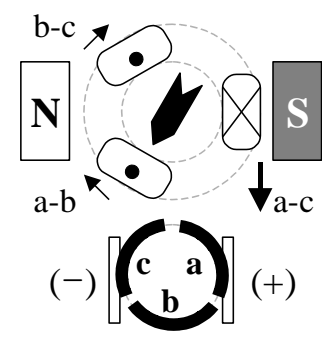

(c) 120-Degrees

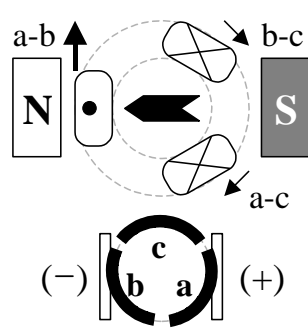

(b) 180-Degrees

Figure 1. Principle of Brush DC-Motor Revolution

\subsubsection{Number of Phase Coil and Torque Ripple}

Since the phase coil is orthogonal to the permanent magnet, the strongest torque is generated in the motor at $0,60,120$ degrees as shown in the Figure 1. At other angles, torque is generated by the resultant force of each phase solenoid. For this reason, there are six strong and weak points per revolution of the rotor, and there are six torque ripples at 3 -phase solenoid. On the same principle, 10 phase torque ripples occur per revolution in 5 phase solenoids as shown in Figure 2(a). The number of ripples $R$ and the number of solenoids $S$ that occur during one revolution of the rotor can be expressed by

$R=S \times 2$,

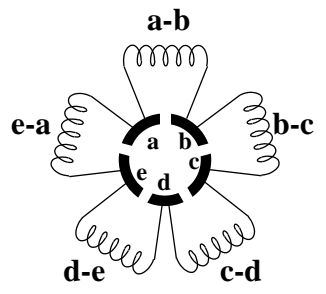

(a) 5-Phase Coils

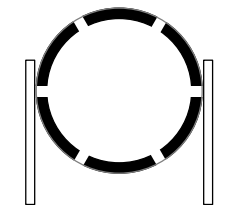

(b) Even Number Coil

Figure 2. Example of Multi-Phase

When the electric motor rotates at a high speed, the torque ripple can be ignored by the inertia of the rotor. However, direct driven automatic door should be considered that torque ripple appears as the physical vibration at low speed operation. The number of rotor-phase coils is generally used an odd number, i.e.

$$
S=2 \cdot n+1, \quad n=1,2,3 \ldots
$$


When $S$ is an even number, the coils are switched simultaneously on both sides of the brush as shown in the Figure 2(b). Since both of the coils simultaneously generate back electromotive force (EMF), brush life is shortened by spark.

\subsection{Requirements for Direct Driven Automatic Door}

\subsubsection{Specifications of Belt Pulley}

The belt pulley of the automatic door is directly coupled to the motor as shown in Figure 3(a). If diameter of the belt pulley is large, the motor should rotate at a lower speed in order to control the door smoothly, and it is more strongly affected by torque ripple. On the other hand, if diameter of belt pulley is too small, there are limitations on the diameter of the motor shaft and anti-slip teeth between the belt and the pulley. Because of its thin thickness, the strength is reduced, and the belt is required for more flexible and it causes belt sagging. For this reason, the minimum diameter of the belt pulley is generally limited to $20 \mathrm{~mm} \varnothing$.

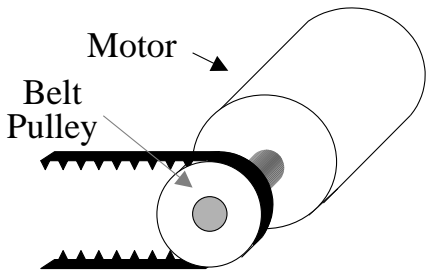

(a) Assembly

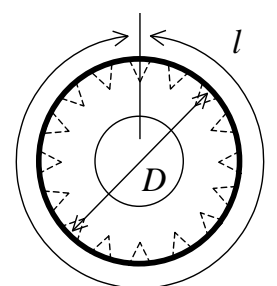

(b) Belt Pulley

\section{Figure 3. Diameter of Belt Pulley}

The diameter of the belt pulley and the circumference of the belt pulley denote $D$ and $l$ respectively. The linear velocity is expressed

$$
v=\pi \cdot D \cdot f
$$

or,

$$
v=l \cdot f
$$

When the belt pulley travels by a revolution (i.e., move by distance $l$ ) as Equation (4), torque ripple is generated by Equation (1). Therefore frequency of torque ripple is obtained by

$$
f_{\text {ripple }}=2 \cdot S \cdot f
$$

Substituting Equation (5) into Equation (3) yields

$$
f_{\text {ripple }}=\frac{2 \cdot S \cdot v}{\pi \cdot D}
$$

It should be noted that the frequency of torque ripple is increased as high speed of motor and the belt pulley diameter is small. Since a maximum speed of $500 \mathrm{~mm} / \mathrm{s}$ is required for a typical automatic door with $20 \mathrm{~mm} \varnothing$ belt pulley, the maximum value of the mechanical revolution velocity is given by Equation (7).

$$
M R V_{\text {max }}=\frac{50 \mathrm{~mm}}{62.83 \mathrm{~mm}}=7.96[\mathrm{Rev} / \mathrm{Sec}]
$$

When the automatic door is almost closed or opened, about $20 \mathrm{~mm} / \mathrm{S}$ is required to prevent door impact. That is, the motor should rotate at low speed as Equation (8)

$$
M R V_{\min }=\frac{20 \mathrm{~mm}}{62.83 \mathrm{~mm}}=0.318[\mathrm{Rev} / \mathrm{Sec}]
$$


Substituting the requirements into Equation (6) yields

$$
f_{\text {ripple }}=\frac{2 \cdot S \cdot 20 \mathrm{~mm}}{\pi \cdot 20 \mathrm{~mm}}=0.637 \cdot \mathrm{S}
$$

For example, when the seven phase solenoids motor is used for automatic door, torque ripple is generated as $4.459 \mathrm{~Hz}$.

The desired frequency of torque ripple is far from natural frequency of the door system which is determined by size and weight of the door. Therefore, the higher the frequency torque ripple (i.e., the more phase solenoids), the better the performance.

\subsubsection{Pulley PWM Control Ratio}

The unit voltage that the resolution of maximum voltage is

$$
V_{\text {step }}=\frac{V_{\max }}{2^{b}}
$$

where, $V_{\max }$ is the maximum voltage of the motor and $b$ is bit for PWM resolution. Rearranging Equation (10), control ratio is obtained by

$$
C R=\frac{V_{\text {step }}}{V_{M}} \times 100=\frac{V_{\max }}{2^{b} \cdot V_{M}} \times 100
$$

where, $V_{M}$ is control output of the system. Assuming that the linear relationship between RPM and voltage, Equation (10) and (11) can be rearranged respectively

$$
N_{\text {step }}=\frac{N_{\max }}{2^{b}}
$$

and

$$
C R=\frac{N_{\text {step }}}{N} \times 100=\frac{N_{\max }}{2^{b} \cdot N} \times 100
$$

Since maximum RPM is inherent factor, the control ratio is determined by resolution of PWM. The control ratio is increased at low speed so that the precise control is difficult at low speed as shown in the Figure 4.

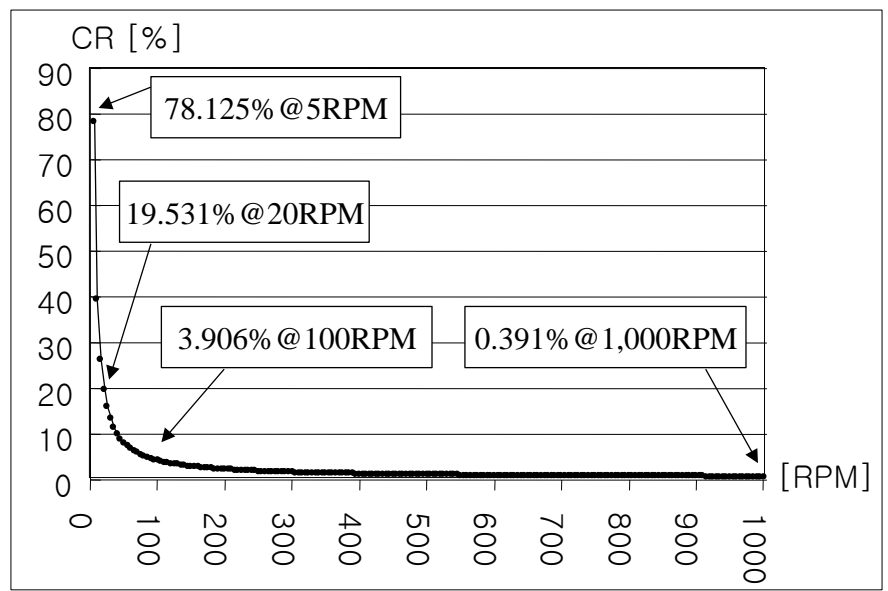

Figure 4. Example of Control Ratio Variation

The desired control ratio is calculated by

$$
b=\log _{2}\left(\frac{N_{\max }}{C R \cdot N} \times 100\right)
$$


Equation (15) and (16) are obtained by maximum number of rotations in Equation (7) and the minimum number of rotations of the motor in Equation (8).

$$
\begin{aligned}
& R P M_{\text {max }}=7.96 \times 60=477.48[R P M] \\
& R P M_{\text {min }}=0.318 \times 60=19.08[R P M]
\end{aligned}
$$

where, $R P M_{\max }$ is assumed to be no load. The resolution of control voltage is calculated by

$$
V_{\text {step }}=\frac{24 \mathrm{~V}}{2^{8}}=93.75[\mathrm{mV}]
$$

where maximum RPM is $1000 R P M$ that margin is doubled as $R P M_{\max }$ considering the load. Also, nominal voltage is $24 \mathrm{~V}$, and controller provides 8 -bit PWM. Therefore, the resolution of RPM is obtained by

$$
N_{\text {step }}=\frac{1000}{2^{8}}=3.906[R P M]
$$

It is feasible to precisely control that control ratio is $0.818 \%$ at 477.48 RPM (i.e., high speed region). On the other hand, it is difficult to control precisely that control ratio is $20.47 \%$ at $19.08 R P M$ (i.e., low speed region). If desired maximum control ratio is 5\%, resolution of PWM is calculated by Equation (19) based on Equation (14).

$$
\left.\log _{2}\left(\frac{1000}{5 \cdot 19.08} \times 100\right)=10.034 \text { [bit }\right]
$$

Figure 10 shows that the RPM curve is nonlinear that the resolution of RPM is reduced at low speed. For this reason, higher resolution for PWM is required to control the motor precisely at low speed. In the experiments, the resolution of PWM is required to 11-bit, if PWM frequency is used to $3.906 \mathrm{KHz}$. Based on this consideration, less than 15-bit is required to control precisely that maximum control ratio is $2 \%$.

\subsubsection{PWM Frequency}

In recent years, as sophisticated control devices have been developed dramatically so that the PWM waveform is generated accurately. Figure 5(a) shows the block diagram of PWM generator in microcontroller, and timing chart of PWM waveform is shown in the Figure 5(b) [10]. The frequency $f_{\text {OSC }}$ which generated from the oscillator drive counter and its binary value compares with the PWM value. When the counter value is higher than PWM value, it will set logical high; otherwise the output will set logical low. Based on this principle, PWM frequency which consists of $b$-bit counter can be obtained by

$$
f_{P W M}=\frac{f_{\text {OSC }}}{2^{b}}
$$

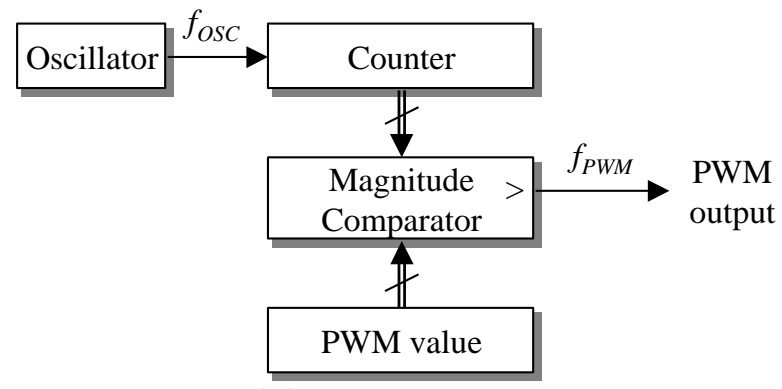

(a) Block Diagram 


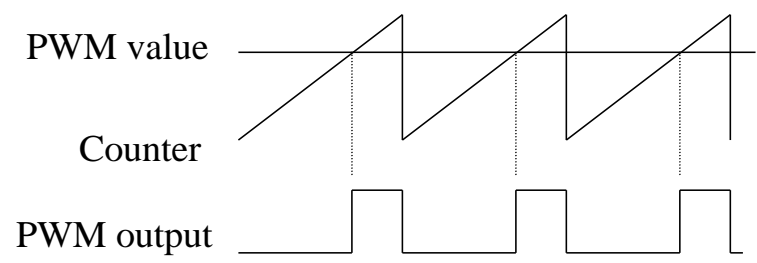

(b) Example of Waveform

Figure 5. Principle of Generation the Digital Type PWM

PWM frequency is proportional to $f_{O S C}$ which is generated by oscillator, and it is inverse proportional to PWM bits by Equation (20). When the PWM frequency is high enough, the angular speed of motor becomes linear as shown in the Figure 10. For example, $5.12 \mathrm{GHz}$ of $f_{\text {OSC }}$ is required to generate $78.125 \mathrm{KHz}$ PWM frequency by 16-bit resolution based on

$f_{\text {OSC }}=78.125 \mathrm{KHz} \times 2^{16}=5.12 \mathrm{GHz}$

\subsubsection{VVPWM (Voltage-Varying Pulse Width Modulation)}

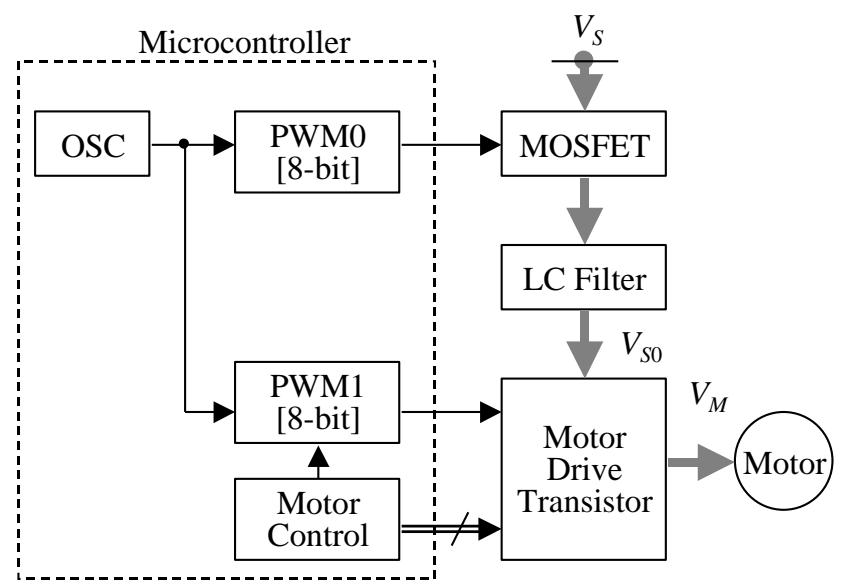

Figure 6. Control Flow of the VVPWM

VVPWM (Voltage-Varying Pulse Width Modulation) is designed for high resolution of speed control with low resolution of PWM. It is consists of dual PWM generator which control the motor drive transistor and a MOSFET respectively as shown in the Figure 6.

$V_{S 0}$ which is generated by MOSFET and LC filter is applied voltage to motor drive transistor. And, $V_{M}$ is generated by controlling PWM1 with $V_{S 0}$. When the time constant of LC filter is large enough, $V_{S 0}$ is determined by $P W M_{0}$ that high frequency components are rejected by filter and a DC component remains. DC component of $P W M_{0}$, which is based on Fourier series, is represented by

$$
V_{S 0}=V_{S} \frac{P W M_{0}}{2^{b 0}}
$$

where $P W M_{0}$ is determined by PWM0 circuit and $b 0$ is a bit of PWM resolution. That is, duty ratio of PWM is obtained by $P W M_{0}$ and $b 0$. Based on Equation (11), the control ratio of PWM0 is calculated by

$$
C R_{0}=\frac{V_{s}}{2^{b 0} \cdot V_{S 0}} \times 100
$$


Substituting Equation (21) into (22) yields

$$
C R_{0}=\frac{1}{P W M_{0}} \times 100
$$

Since the $P W M_{1}$ controls $V_{M}$ with $P W M_{0}$, the minimum control ratio of $P W M_{1}$ is Equation (23). The control output $V_{M}$, which is controlled by $P W M_{1}$, is

$$
V_{M}=V_{S 0} \cdot \frac{P W M_{1}}{2^{b 1}}
$$

Although $V_{S 0}$ is DC voltage, PWM1 should control the motor due to the low response time of LC filter. The control ratio of PWM1 is calculated by

$$
C R_{1}=\frac{V_{S 0}}{2^{b 1} \cdot V_{M}} \times 100
$$

Substituting Equation (24) into (25) yields

$$
C R_{1}=\frac{1}{P W M_{1}} \times 100
$$

The PWM value for a specific $C R$ is obtained by

$$
P W M_{1}=\frac{1}{C R_{1}} \times 100
$$

\subsection{Simulation}

Figure 7 shows the simulation results for controlling the motor that $C R$ is $5 \%$ at operation range. It is assumed that relationship between the PWM duty ratio and RPM has linearity.

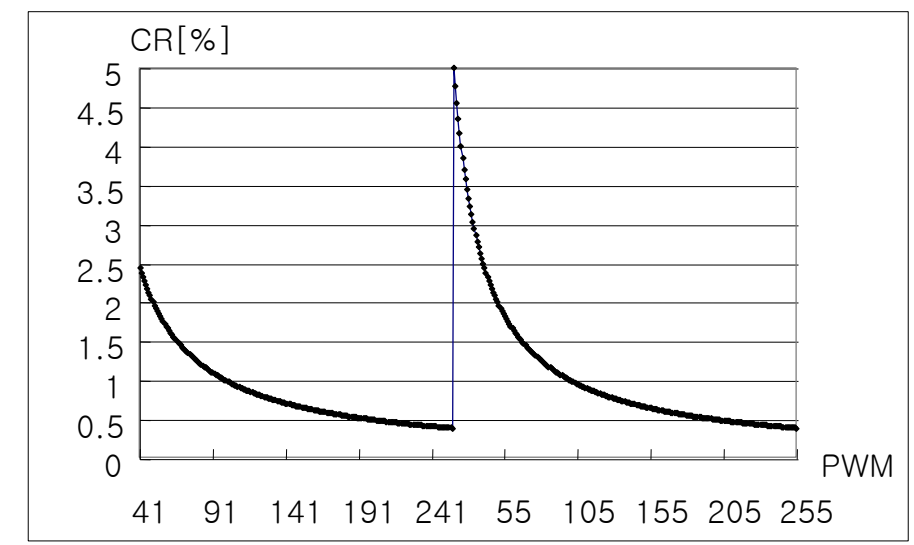

(a) Control of PWM1 


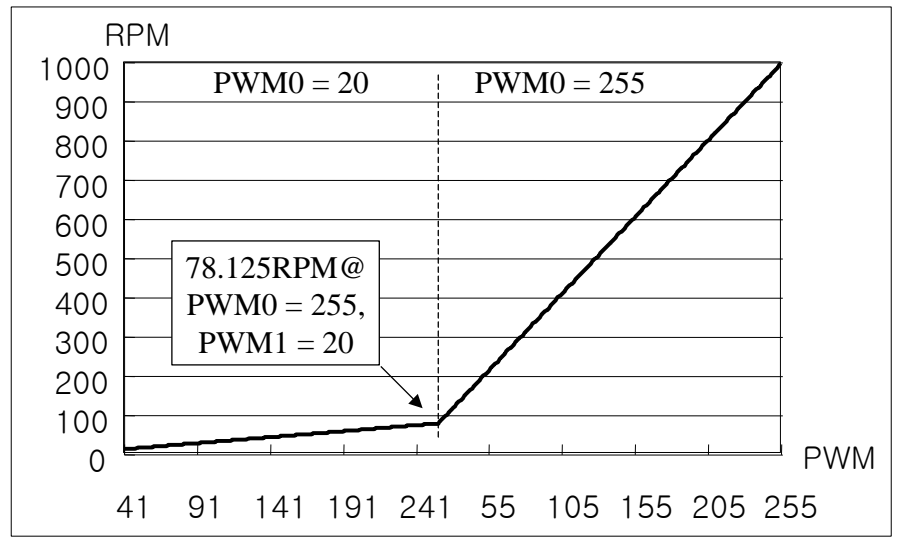

(b) Variation of Revolution

Figure 7. Simulation at $N_{\max }=1,000, b 1=b 2=8, C R<5 \%$

Note that if PWM0 is maximum value and PWM1 is decreased, the control ratio is gradually increased and the motor speed is decreased. When the control ratio reaches at $5 \%$ (i.e., PWM1 $=1 / 5 \times 100=20$ ), PWM0 is controlled as 20 (i.e., PWM0 $=1 / 5 \times 100=$ 20) and PWM1 is set for maximum value, which implies 5\% of control ratio.

In Figure 7(b), the RPM of motor is varied by PWM0 and PWM1, which is expressed as double slope decay. In the low speed region, precise speed control is realized by VVPWM method; the automatic door can be controlled by $19.1 R P M$ with $1.598 \%$ control ratio. Also, when the PWM1 reach the 20, which is saturation of PWM1, VVPWM method can maintain control ratio by reducing PWM0.

Notice that the relationship between the PWM duty ratio and RPM is assumed to be linear. Although, PWM function has inherent nonlinearity in the voltage-speed relationship, such nonlinearities are to be reduced by VVPWM because PWM1 starts at $100 \%$ again at low speed. Figure 8 shows the simulation results for controlling $C R=2 \%$. VVPWM method can not only generates high frequency PWM $(78.125 \mathrm{KHz})$ using 20 $\mathrm{MHz}$ microcontroller with 8-bit PWM resolution, but also control precisely at low speed. Therefore, the nonlinearity in the voltage-speed relationship can be greatly improved.

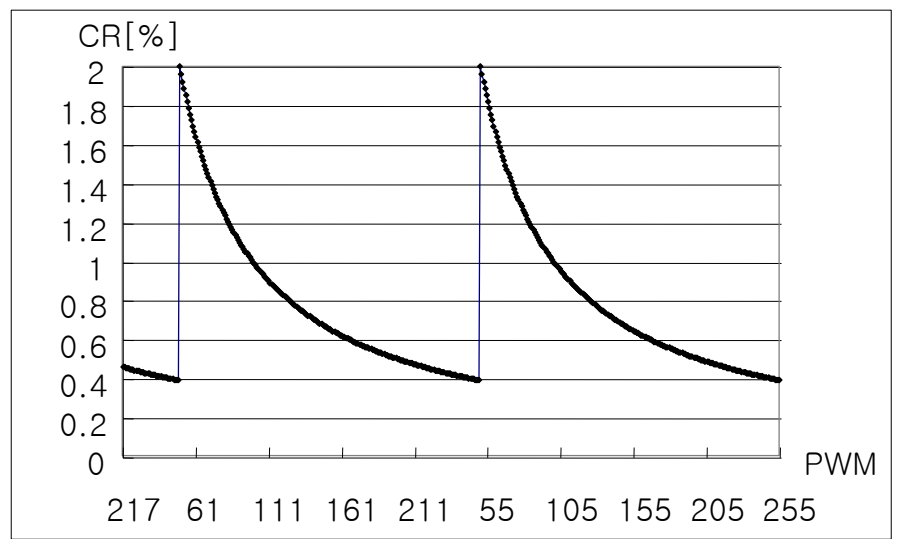

(a) Control of PWM1 


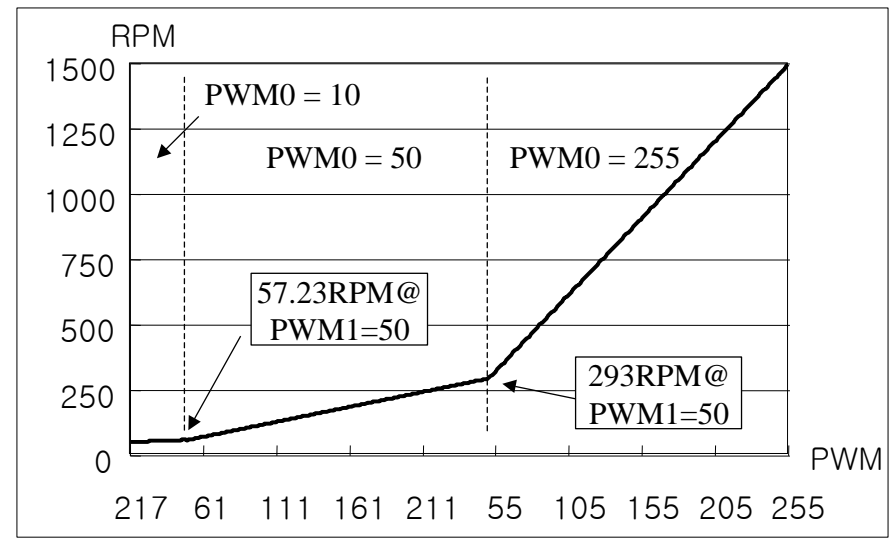

(b) Variation of Revolution

Figure 8. Simulation at $N_{\max }=1,000, b 1=b 2=8, C R<2 \%$

\section{Experiments and Considerations}

In order to verify the characteristics of low-speed operation, an experimental test-bed was set which includes proposed circuit as shown in the Figure 6 and electric motor as shown in the Figure 9.

Made in China

Nominal voltage : $24 \mathrm{~V}$

Terminal resistance : $16 \Omega$

Terminal inductance : $1.2 \mathrm{mH}$

Angular speed constant : $K_{N}=41.7 R P M / V$

Back-EMF constant : $K_{B}=7.08 m V / R P M$

\section{Figure 9. Specifications of Motor for Experiment (Measured Value)}

Figure 10 shows the experimental results in the duty ratio - RPM with three different frequencies. The result shows that high frequency PWM can improve the linearity.

Figure 11 focuses on the low speed region of Figure 10 with the best linearity of 78.125 KHz PWM and VVPWM. In the zoomed-in graphs shown in Figure 11(b), the improvement of the RPM resolution is clearly shown. Motor speed was reduced as $4 R P M$ per bit by PWM. On the other hand, it was reduced as $0.3 R P M$ per bit by VVPWM which is 13.33 times higher precision than conventional PWM. Therefore, the motor speed can be controlled with an accuracy of $1.572 \%$ at low speed less than 19.08 RPM. 


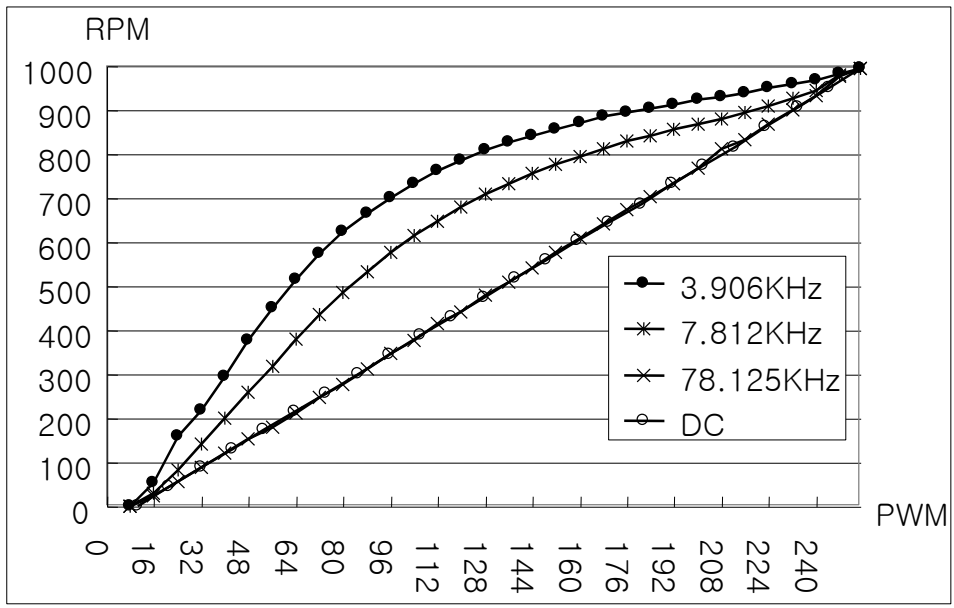

Figure 10. Graph of Revolution at Various PWM Frequencies

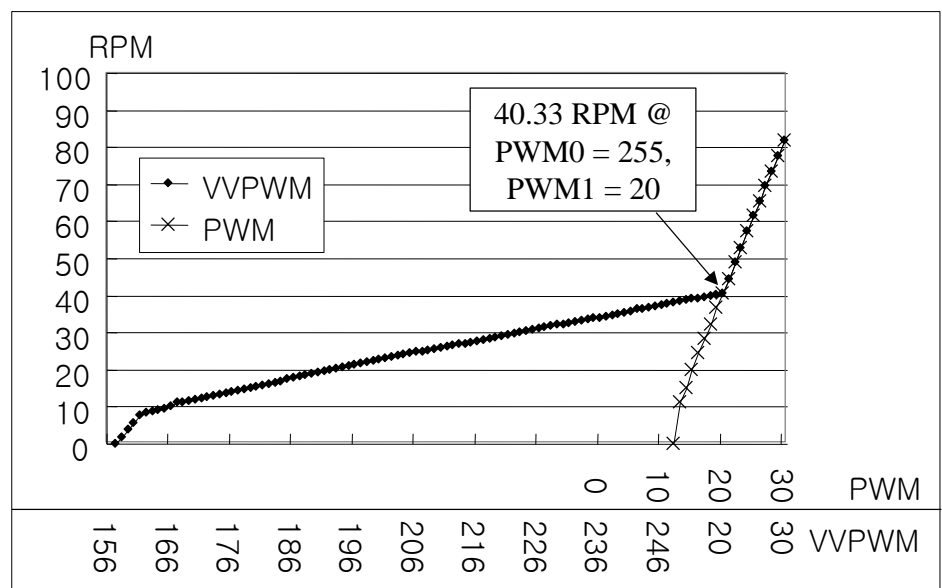

(a) Part of Very-Low Speed

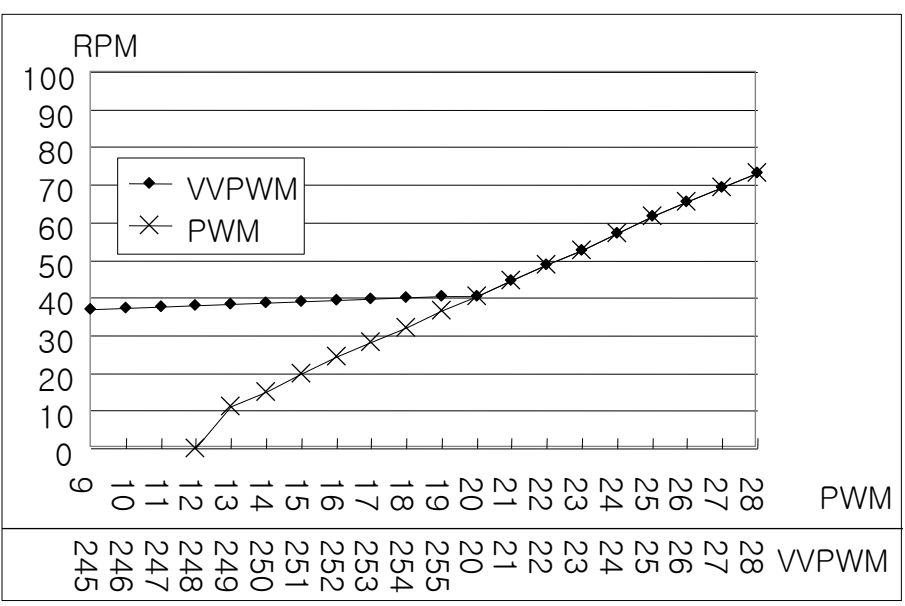

(b) Graph of Partial Enlarged

Figure 11. Comparison of Results at PWM, VVPWM 


\section{Conclusion}

In this paper, VVPWM (Voltage Varying Pulse Width Modulate) is proposed that direct driven automatic door is controlled smoothly at low speed. In order to prevent vibrations of the doors at low speed, it is more advantageous to have more solenoids on the rotor. An automatic door motor with a $20 \mathrm{~mm} \varnothing$ belt pulley is required to operate from $477.48 R P M$ to $19.08 R P M$. It is possible to control precisely not only high speed operation region but also low speed operation region of the automatic door with VVPWM; high frequency PWM is unnecessary. In order to verify the effectiveness of the VVPWM, experimental system is designed as dual PWM generator built into the $20 \mathrm{MHz}$ microcontroller. Experimental results show that the conventional PWM controls an average of $4 R P M$ over the entire operating range of the motor. On the other hand, the VVPWM controls an average of $0.3 R P M$ at low speed while applying a high PWM frequency of $78.125 \mathrm{KHz}$. It is notice that VVPWM can control the motor with 13.33times higher precision than conventional PWM.

\section{Acknowledgments}

This paper is a revised and expanded version of a paper entitled [Analysis of Driving Limitation at Very-low speed in DC-motor] presented at [Hyunchang Lee, ICGHIT 2017 Hangzhou China, February 2017].

\section{References}

[1] H.C. Lee, "Apparatus and Method for Controlling Automatic Door using Brushless Direct Current Motor”, Korea Patent 10-1639695(KR101639695B1), (2016).

[2] H.C. Lee, K. T. Lee and J.E. Lee, "Analysis of Driving Limitation at Very-low speed in DC-motor", ICGHIT 2017 conference, Hangzhou China, (2017), pp. 304-305,.

[3] M. Lee, J. Lee, K. Kim, M. Choi and K. Kong, "Dynamic Characteristics of High Speed BLDC Motors and High Torque BLDC Motors", Conference of the Korean Society of Mechanical Engineers, Korea, (2015), pp. 3362-3367.

[4] T.S. Low, K.J. Tseng, T.H. Lee, K.W. Lim and K.S. Lock, "Strategy for the instantaneous torque control of permanent-magnet brushless DC drives", IEE Proceedings B - Electric Power Applications, vol. 137, no. 6, (1990), pp. 355-363.

[5] J.H. Kim, K.H. Cho and H.W. Kim, "Torque Ripple Reduction Algorithm of PM Synchronous Motor at High Speed Operation”, Transactions of the Korean Institute of Power Electronics, vol. 20, no.5, (2015), pp.429-436.

[6] S. Funabiki and T. Himei, "Estimation of torque pulsation due to the behaviour of a converter and an inverter in a brushless DC-drive system", IEE Proceedings B - Electric Power Applications, vol. 132, no. 4, (1985), pp. 215-222.

[7] J. Tal, "Optimal commutation of Brushless Motors", Incremental Motion control systems and devices, (1982), pp.49-53.

[8] M. Lee and K. Kong, "Fourier-series-based Phase Delay Compensation of Brushless DC Motor Systems", IEEE Transactions on Power Electronics, ieeexplore.ieee.org/ abstract/document/7855832, (2017).

[9] T. Kenjo and S. Nagamori, "Permanent Magnet and Brushless DC Motors", Sogo Electronics Publishing Company, Tokyo, (1984), pp. 4-9.

[10] Atmel Corp., ATmega48A/88A/168A - Complete Datasheet (http://www.atmel.com), (2016), pp. 135142. 

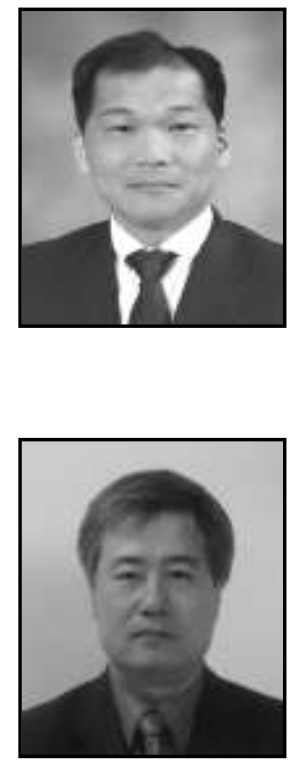

\section{Authors}

Hyun-Chang Lee, he received his B.S. in Electronics Engineering from Dankook University, Korea, 1986 and M.S. degree in Electronics Engineering from Dankook University, Korea, 1988 and $\mathrm{Ph}$.D. degree in Electronics Engineering from Dankook University in 1996. He joined the faculty of Kongju National University, Korea where he is currently a professor in Division of Information and Communication Engineering. His research interests include Analog/ Multimedia circuit, Micro-controller Applications, Firmware by assembly language and Circuit for Mechatronics.

Kyu-Tae Lee, he received his B.S. in Electronics Engineering from Korea University, Korea, 1984 and M.S. degree in Electronics Engineering from Korea University, Korea, 1986 and Ph.D. degree in Computer and Electronics Engineering from Korea University in 1991. He joined the faculty of Kongju National University, Korea where he is currently a professor in Division of Information and Communication Engineering. His research interests include DSP programming, Reconfigurable open architecture, Software Defined Radio system and Circuit and System. He is a member of IEIE(Institute of Electronics and Information Engineers). 